\title{
EFFECT OF LEAF TYPE ON THE OVICIDAL ACTIVITY OF HEXYTHIAZOX
}

\author{
J.W.M. MARRIS and R.B. CHAPMAN \\ Entomology Department, Lincoln College, Canterbury
}

\section{SUMMARY}

Laboratory tests to determine the effect of leaf type on the toxicity of hexythiazox to two-spotted mite eggs were carried out. Hexythiazox was most toxic to eggs laid on broad bean leaves, least toxic to those laid on the leaves of the apple cultivars 'Red Delicious' and 'Granny Smith' and of intermediate toxicity to those laid on raspberry and strawberry leaves. Possible reasons for this variation in toxicity are discussed.

\section{INTRODUCTION}

Spider mites are frequent pests on many horticultural crops and commonly require regular applications of miticide to maintain their numbers below damaging levels. Several new ovicidal miticides have been introduced recently (Read 1983; Chapman and Marris 1986) but as yet little is known about what influences their efficacy. One possible factor is the effect of leaf type. Asano and Kamei (1982) observed variation between the responses of Panonychus citri and Tetranychus urticae to the ovicide cycloprate on different leaf types and forwarded several explanations for their results. Because the eggs of spider mites are mostly laid on the under surfaces of leaves and surface morphology of leaves can vary quite markedly between plant species and cultivars, an experiment evaluating the effect of leaf type on the toxicity of hexythiazox to twospotted mite (TSM) eggs was carried out.

\section{METHODS}

TSM were reared in the laboratory on French dwarf beans (Phaseolus vulgaris cv. 'Tendergreen'). The TSM strain (AKl) originated from a commercial rose house in Auckland where an intensive pesticide spray programme had been used. Laboratory tests had earlier shown the mites to be moderately resistant to organophosphorus insecticides but not resistant to common miticides, e.g. cyhexatin (Chapman, unpublished).

A modified leaf disc technique (FAO 1974) was used to determine the toxicity of hexythiazox (Nissorum $10 \mathrm{WP}, 100 \mathrm{~g}$ ai $/ \mathrm{kg}$ ) to TSM eggs laid on leaves of the different leaf types. The leaf types used were broad bean (Vicia faba cv. 'Exhibition Long Pod'), strawberry (Fragaria ananassa cv. 'Red Gauntlet'), raspberry (Rubus ideaus cv. 'Glen Prosen') and apple (Malus sp. cv. 'Red Delicious' and 'Granny Smith'). Ten leaf discs of $10 \mathrm{~mm}$ diameter were placed upper surface down on damp cotton wool in petri dishes. Ten to 15 adult TSM females were placed on each disc and allowed to oviposit for $24 \mathrm{~h}$ at $25 \pm 0.5^{\circ} \mathrm{C}$ and $85 \pm 5 \% \mathrm{RH}$ in a $16: 8 \mathrm{~h} \mathrm{~L}$ :D photoperiod. Females were removed after this period and the numbers of eggs counted.

The leaf discs were then sprayed under a Potter tower $(102 \mathrm{kPa}, 10 \mathrm{sec}$ settling time) with $1.5 \mathrm{ml}$ aqueous suspensions of hexythiazox. A range of five concentrations and a water-sprayed control were prepared for each leaf type. After spraying, the leaf discs were air dried for $30 \mathrm{~min}$ before being placed in covered plastic trays in a controlled environment cabinet where they remained for 5 to 6 days under the conditions described above. Egg mortality was assessed after this period.

The data were analysed by probit analysis using the computer programme POLO (Russell et al 1977). The $\mathrm{LC}_{50}, 95 \%$ confidence interval, slope of the regression line and its standard error were calculated for each leaf type. Significant difference between $\mathrm{LC}_{50}$ values were determined by non-overlap of $95 \%$ confidence intervals.

Proc. 40th N.Z. Weed and Pest Control Conf. 
To gain some information on the surface morphology of each leaf type, discs on which TSM had laid eggs were examined using a scanning electron microscope at magnifications up to ca. 360 times.

\section{RESULTS}

The relationships between $\log$ concentrations and probit mortality for each leaf type are shown in Figure 1. A summary of the probit analyses is presented in Table 1.

Plots of the regression lines (Figure 1) immediately indicated that there were differences between the susceptibility of TSM eggs to hexythiazox on different leaf types. Eggs laid on broad bean were the most susceptible whereas those laid on 'Granny Smith' were the most tolerant. When $\mathrm{LC}_{50}$ values were values were compared (Table 1), this difference is a factor of 6.2. There was no significant difference between the $\mathrm{LC}_{50}$ values of the two apple cultivars or between raspberry and strawberry, but these two groups were significantly different from each other and from the $\mathrm{LC}_{50}$ for broad bean.

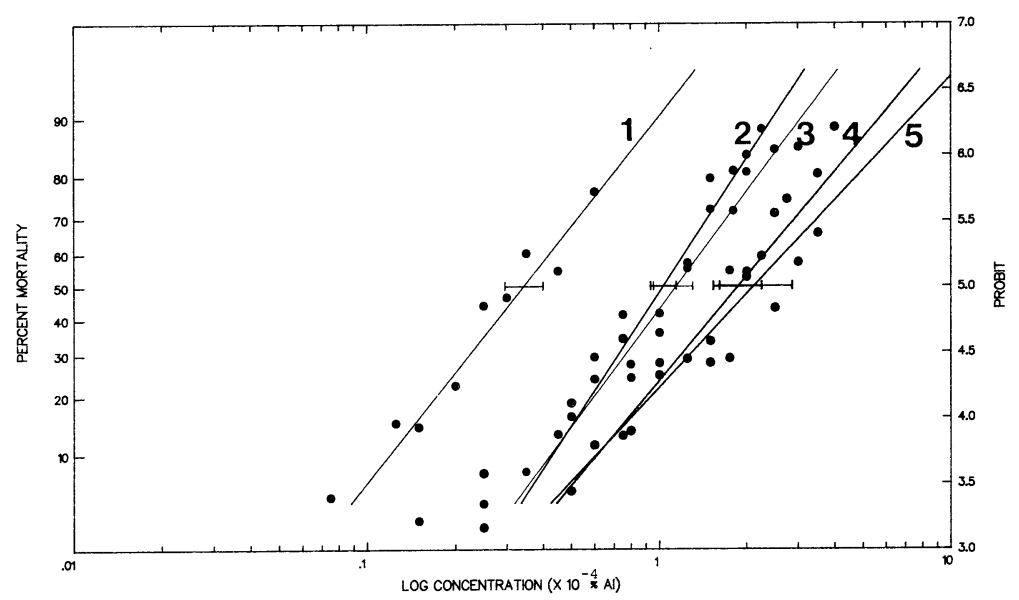

Fig. 1: Responses of two-spotted spider mite to hexythiazox on different leaf types. $(1=$ broad bean, 2 = raspberry, $3=$ strawberry, $4=$ 'Red Delicious', $5=$ 'Granny Smith').

TABLE 1: Toxicity of hexythiazox to two-spotted mite eggs on different leaf types.

\begin{tabular}{lccccc}
\hline Leaf Type & $\begin{array}{c}\text { No. eggs } \\
\text { tested }\end{array}$ & $\begin{array}{c}\mathrm{LC}_{50} \\
\text { \% ai x } 10^{-4}\end{array}$ & 95 \% CI & Slope & SE \\
\hline broad bean & 2364 & $0.34 \mathrm{a}^{\prime}$ & $0.30-0.40$ & 2.79 & 0.18 \\
raspberry & 4799 & $1.03 \mathrm{~b}$ & $0.93-1.15$ & 3.38 & 0.16 \\
strawberry & 5802 & $1.14 \mathrm{~b}$ & $0.94-1.21$ & 2.97 & 0.14 \\
$\begin{array}{c}\text { apple } \\
\text { 'Red Delicious' } \\
\text { apple }\end{array}$ & 6095 & $1.87 \mathrm{c}$ & $1.54-2.26$ & 2.64 & 0.11 \\
'Granny Smith' & 3832 & $2.12 \mathrm{c}$ & $1.61-2.86$ & 2.37 & 0.17 \\
\hline
\end{tabular}

Values with the same letters are not significantly different as $95 \%$ confidence intervals overlap.

\section{DISCUSSION AND CONCLUSIONS}

Leaf type has been shown to be an important factor influencing the toxicity of hexythiazox to TSM eggs. Ovicidal activity for the different leaf types decreased in the following order: broad bean, raspberry, strawberry, 'Red Delicious apple, 'Granny Smith' apple. The 6.2 fold difference in LC $_{50}$ values between broad bean and 'Granny Smith' was greater than that found by Asano and Kamei (1982) for TSM eggs on a 
range of leaf types treated with cycloprate. They concluded that leaf hair density could be one factor influencing the results of their experiment as lower $\mathrm{LC}_{50}$ values were always recorded for relatively hairless leaves like peach and pear compared with apple. Furthermore, the ovicidal activity of cycloprate against TSM eggs on apple was three times higher on the upper than on the lower surface and this was again attributed to the relative difference between leaf hair densities. Precisely why leaf hair density should influence the toxicity of an ovicide to TSM eggs was not determined but it could presumably be related to the penetration, distribution or movement of the active ingredient on a leaf surface.

Our results from this study with hexythiazox cannot be entirely explained by relative differences in leaf hair densities. Examination of electron micrographs of the various leaf surfaces showed broad bean to have relatively few leaf hairs (glabrate vestiture) on the lower surface whereas both apple cultivars had relatively more leaf hairs of a pilose nature. However, raspberry had an extremely dense profusion of hairs on the lower surface (tomentose vestiture) yet on this hexythiazox was intermediate in toxicity between broad bean and the apple cultivars. It was also interesting to note that TSM eggs were invariably laid on the leaf surface between leaf hairs on all leaf types except raspberry where they were laid on the dense mat of leaf hairs. Therefore, both leaf hair type and density as well as oviposition site may well be factors influencing the efficacy of ovicides.

Eggs laid on relatively hairless leaf surfaces would be more exposed to direct contact by spray droplets. However, evidence by Munthali and Wyatt (1986) indicates this may not be such an important factor as they found less than 5\% of TSM eggs were directly hit by dicofol-in-oil droplets of $100 \mu \mathrm{m}$ diameter. They concluded more egg deaths resulted from dicofol being transported across the leaf surface and that droplet spacing and perimeter were the two most important factors influencing the spread of toxicant. In this study, the Potter tower produced a volume median droplet diameter of $42 \mu \mathrm{m}$, and a deposit of $0.00087 \mathrm{ml} / \mathrm{cm}^{2}$ wet spray. Hexythiazox also has some translaminar activity (Anon 1984), which could be significant in the poisoning of TSM eggs.

Applied spray volume may be a further factor affecting the toxicity of the ovicide to TSM eggs since different spray volumes will deposit different amounts of active ingredient on the leaf surface. Wakou and Sugawara (1974) found the $\mathrm{LC}_{50}$ values for dicofol varied between leaf type (apple, bean, peach) and spray volume applied. The greatest difference between leaf types was found with the lowest spray volumes. Indirectly this suggests, for a given concentration, droplet density is a primary determinant of miticide efficacy on different leaf types. It also indicates that the results of such bioassays are very technique dependent and may not reflect field conditions.

While the results of this study illustrated significant differences in the efficacy of hexythiazox on different leaf substrates, such differences are unlikely to be important in field situations as the recommended field concentration $(0.025 \mathrm{~g}$ ai/litre $)$ far exceeds the values in Table 1. However, they do indicate the necessity to evaluate a product such as hexythiazox on a range of TSM host plants to be assured the desired control can be achieved.

\section{ACKNOWLEDGEMENT}

Financial assistance provided by May and Baker New Zealand Ltd is gratefully acknowledged.

\section{REFERENCES}

Anonymous, 1984. NISSORUN (NA-73); A new acaricide. Japanese Pesticide Information No. 44: 21-24.

Asano, S. and Kamei, M., 1982. Ovicidal activity of cycloprate for several phytophagous mite species and its relationship with test host plants. Appl. Ent. Zool. 17: 67-74.

Chapman, R.B. and Marris, J.W.M., 1986. The sterilising effect of clofentezine and hexythiazox on female twospotted mite. Proc. 39th N.Z. Weed and Pest Control Conf.: 237-240. 
FAO, 1974. Recommended methods for the detection and measurement of resistance of agricultural pests to pesticides: Tentative methods for spider mites and their eggs, Tetranychus spp. and Panonychus ulmi (Koch) - FAO Method No. 10. FAO Plant Protection Bulletin 22: 103-106.

Munthali, D.C. and Wyatt, I.J., 1986. Factors affecting the biological efficacy of small pesticide droplets against Tetranychus urticae eggs. Pesticide Science 17: 155-164.

Read, A.J., 1983. Bisclofentezine - a novel compound for control of phytophagous mites. Proc. 36th N.Z. Weed and Pest Control Conf.: 265-268.

Russell, R.M., Robertson, J.L. and Savin, N.E., 1977. POLO: a new computer program for probit analysis. Bull. Ent. Soc. America 23: 209-213.

Wakou, M. and Sugawara, H., 1974. Studies on improvement of tests for acaricides. 1. Importance of leaves used for leaf disc method. Bulletin of the Fruit Tree Research Station. Series C: 129-139. 